\title{
Selection of private or public hospital care: examining the care-seeking behaviour of patients with private health insurance
}

\author{
Rezwanul Hasan Rana ${ }^{1 *}$, Khorshed Alam $^{2}$ (D) and Jeff Gow ${ }^{1,3}$ (D)
}

\begin{abstract}
Background: This study aimed to examine the healthcare-seeking (hospital, primary and preventive care) and healthcare utilisation behaviour of patients with private health insurance (PHI) in Australia. It also aimed to examine the socioeconomic, demographic and lifestyle factors that influence the choice of hospital care in Australia.

Method: A logistic regression model with repeated measure t-test and Pearson's Chi-square test were used to identify the factors that affect the choice of care. Data from waves 9 (2009) and 13 (2013) of the nationallyrepresentative Household, Income and Labour Dynamics in Australia (HILDA) survey were used in the analysis.

Results: Patients with PHI had a higher number of hospital nights' stay despite having a lower number of hospital admissions than those without private cover. Significant disparities were identified in preventive and specialist care use between patients with cover and without cover. No significant variations were observed in healthcare utilisation for $\mathrm{PHI}$ patients before and after dropping PHI. One in four patients chose to use public hospitals despite holding PHI cover. Moreover, those insured and from lower socioeconomic backgrounds and those who were younger and without long-term health conditions showed a higher probability of selecting public rather than private care.

Conclusions: It is evident that PHI cover encourages people to use private care. However, a considerable number of $\mathrm{PHI}$ patients are using public care, even though eligible for private care may indicate consumer information asymmetry.
\end{abstract}

Keywords: Australia, Care-seeking, Healthcare use, Hospitals, HILDA, Private health insurance

\section{Background}

In the emergency department of Australian public hospitals, patients with private health insurance (PHI) are asked to decide whether they want to be treated as public or private patients. Interestingly, for people with PHI cover, the answer is not always obvious. The policies promoting PHI in Australia often focus on increasing its attractiveness to promote private health care usage and

\footnotetext{
*Correspondence: rezwanul_54@yahoo.com; rezwanul.rana@usq.edu.au ${ }^{1}$ School of Commerce, University of Southern Queensland, Toowoomba, Australia

Full list of author information is available at the end of the article
}

thus reduce pressure on the public system [1]. A recent report published by the 'Senate Community Affairs Reference Committee' found that patients are often unaware of the potential out-of-pocket treatment costs when using the private health system [2]. Many patients with PHI cover do not opt for private hospital care but instead end up in public hospitals undermining the policy aim of redirecting public hospital demand to the private sector. Higher enrolment rates for PHI will not save scarce public resources unless the PHI system encourages those patients to use private hospitals solely. In addition, a PHI system that promotes unequal access to

C C The Author(s). 2020 Open Access This article is licensed under a Creative Commons Attribution 4.0 International License, which permits use, sharing, adaptation, distribution and reproduction in any medium or format, as long as you give appropriate credit to the original author(s) and the source, provide a link to the Creative Commons licence, and indicate if changes were made. The images or other third party material in this article are included in the article's Creative Commons licence, unless indicated otherwise in a credit line to the material. If material is not included in the article's Creative Commons licence and your intended use is not permitted by statutory regulation or exceeds the permitted use, you will need to obtain permission directly from the copyright holder. To view a copy of this licence, visit http://creativecommons.org/licenses/by/4.0/ The Creative Commons Public Domain Dedication waiver (http://creativecommons.org/publicdomain/zero/1.0/) applies to the data made available in this article, unless otherwise stated in a credit line to the data. 
care is also undesirable. Hence, to improve overall outcomes in the health care system, it is imperative to understand the factors influencing the choice facing patients with PHI and their use of medical care services in Australia.

Previous studies related to PHI in Australia have mainly focused on the factors determining patients' decision to purchase PHI cover [3, 4], the adverse selection problem (at a given premium high-risk individuals will have more incentive to purchase PHI than low-risk individuals) [5] and whether PHI increases utilisation of hospital care [6] and other medical treatments [7]. Others argued for [3, 6] and against $[1,8,9]$ the justification of providing public subsidies to take up PHI via tax rebates and other fiscal incentives. Little is known regarding the hospital and preventive care-seeking attitudes of patients with and without PHI cover in Australia. Moreover, it is still unclear what socioeconomic and demographic factors influence patients with PHI cover to access public hospitals as a public patient despite paying for and having the availability of private hospital care. Lastly, to the best of authors' knowledge, no study has yet examined the differences in healthcare utilisation for patients who held and then dropped PHI cover. A nationally representative survey data set is used to examine these issues.

To address these gaps in the literature, this paper aims to examine the disparity in healthcare use of individuals with and without PHI cover and to identify the socioeconomic, demographic, geographic and lifestyle characteristics that influence the choice of hospital care (public vs private) of patients with PHI. Equality of access is a major goal of the Australian health system through Medicare, the national health insurance scheme. Yet simultaneously, public resources are directed towards individuals and organisations to promote private healthcare which is in conflict with that aim. There seems to be little justification for promoting PHI if it does not considerably reduce public sector demand. The findings of this study will assist in the discussion of the optimal policy mix to address the issues of access and equity in the Australian hospital system.

This study will add to the existing literature by answering the following research questions: i) to what extent does the hospital care-seeking attitudes and use of secondary preventive and specialist care vary between those with or without PHI cover?; ii) what factors influence the choice of the type of hospital care (public vs private) among patients with PHI cover? and iii) does healthcare use differ significantly for individuals before and after dropping PHI cover?

These issues are particularly important concerns for countries where universal public healthcare is supplemented by a privately funded health system (e.g. Australia, Ireland, Canada and the UK). The findings will assist policymakers to realise whether current healthcare policy settings which promote PHI are effective in reducing demand for public hospital care. Further analysis will reveal whether PHI cover encourages people to consume additional healthcare services. Moreover, understanding the factors influencing hospital care-seeking behaviour of patients with PHI cover will offer policy guidance based on consumer demand and actual use of health services.

\section{Australian healthcare system in brief}

The study setting of this paper is Australia, a developed country that has a sound and relatively sophisticated healthcare system which ranks very high internationally and also amongst the Organisation for Economic Cooperation and Development (OECD) countries [10, 11]. The population of Australia enjoys higher life expectancy, lower infant mortality and fewer disability-adjusted life years compared to the OECD country average while the share of national healthcare expenditure to gross domestic product (GDP) is at the median among OECD countries [12]. Residents of Australia (in 2018) had a higher average number of doctor consultations and a lower average length of stay in hospital and fewer waiting days for elective surgery compared to the average in OECD countries [13]. For instance, the median waiting days for Cataract surgery, Coronary bypass and Hip replacement in Australia were 85 days, 13 days and 110 days, respectively, compared to the OECD average of 103 days, 22 days and 128 days. Hence, if health status and use of healthcare services are principal indicators of the performance of a healthcare system, Australia's health sector is doing an efficient job in comparison to other OECD countries.

The federal, state and territory governments of Australia share the responsibility to finance, develop and implement policies, and regulate and monitor the healthcare system. The health system is a multi-layered network of public and private service providers and supporting mechanisms [12]. Healthcare is provided through general practitioners (GPs) (primary care services), medical specialists, allied health workers, hospitals, nurses and other health professionals.

The universal tax-funded public health insurance program in Australia is called 'Medicare'. It has three major parts: medical services, public hospitals and medicines. It covers the expenses of public hospital services (free treatment for patients in public hospitals) and visits to doctors (payment of benefits or rebates for using selected professional healthcare services through the 'Medicare Benefits Schedule') [14]. Further, the 'Pharmaceutical Benefits Scheme' provides subsidies for a variety of prescription medicines. Hence, the fundamental structure of the hospital and medical services has been 
established in a way to provide essential healthcare services to all Australians without experiencing financial hardship [15].

The Australian healthcare system is often called a hybrid model because, in addition to Medicare, people can also purchase private health insurance to gain access to both public and private hospitals as private patients [16] and extra coverage of services (e.g. dental care and physiotherapy), items not covered by Medicare [17]. Australian health policy encourages private health cover (through tax incentives or monetary rebates on premiums) so that private hospital care can complement (but sometimes duplicate) the services provided by public hospitals. The aim is to reduce public healthcare expenditure and improve access to and quality of the public health sector [18]. Hence, promoting PHI is a pivotal mechanism to manage the rising burden of healthcare demand for the rapidly ageing Australian population. Moreover, PHI also provides patients with more options regarding their choice of doctors and type of services [6]. Nonetheless, the policy of subsidising private health insurance through the tax system is a contentious issue, and some argue that it creates inequality in access to care [19].

Healthcare in Australia is financed using a mixture of public and private sources [17]. According to the Department of Health in $2016-17,41 \%$ of healthcare costs were financed by the Federal Government, $27 \%$ by the six state and two territory governments, $17 \%$ by individuals, $9 \%$ by private health insurers and $6 \%$ by nongovernment organisations [20]. Eventually, all healthcare spending is financed by households through taxation, out-of-pocket expenditure or private health insurance premiums [21]. In total, there were 695 public and 630 private hospitals in Australia (in 2016) [22]. Figure 1 provides a basic health funding flowchart of the Australian health sector. It is important to note that some households contribute more than others, and some utilise healthcare services more than they contribute.
Hence, the health financing mechanism is redistributive and focused on achieving equity in access, regardless of socioeconomic status.

Figure 2 shows the choice of hospital care type by age group and the trends in the number of persons insured in Australia. Expectedly, as age increases, so does the use of all types of hospital care. The propensity for the selection of private care in preference to public care, increases at an increasing rate after the age of 50 (Fig. 2). On the other hand, Fig. 2 also indicates the decreasing trend of the total number of people with PHI cover. Further information on the current state of PHI and Australian hospitals is available from a recent report published by the Australian Institute of Health and Welfare (AIHW) [23].

\section{The conceptual framework}

This study seeks to understand the relationship between PHI status and the medical care-seeking attitude of patients with PHI cover in Australia. Having PHI cover is desirable as it provides patients with more choices regarding doctors, type of services and reduced waiting times while protecting patients from additional healthcare expenditures not covered by 'Medicare' $[3,6]$. Hence, following van Gameren [24], the consumption of health services by a patient (with PHI cover) from a utility maximisation perspective can be divided into two parts: consumption of publicly $\left(\mathrm{H}_{\mathrm{pb}}\right)$ and privately funded healthcare $\left(\mathrm{H}_{\mathrm{pt}}\right)$. If $\mathrm{C}$ is the consumption of all other goods and $\mathrm{M}$ is the total income then, the utility maximisation function restricted by income (total expenses are not higher than income) is,

$$
\begin{aligned}
& \operatorname{Max} U\left(\mathrm{C}, \mathrm{H}_{\mathrm{pb}}, \mathrm{H}_{\mathrm{pt}}\right) \\
& \mathrm{M} \geq \mathrm{P}_{\mathrm{pb}} \mathrm{H}_{\mathrm{pb}}+\mathrm{P}_{\mathrm{pt}} \mathrm{H}_{\mathrm{pt}}+\mathrm{P}_{\mathrm{c}} \mathrm{C}
\end{aligned}
$$

where $\mathrm{P}_{\mathrm{pb}}$ is the price of public health services, $\mathrm{P}_{\mathrm{pt}}$ is the price of private health services, and $P_{c}$ is the price of all other consumption goods. Although the demand for

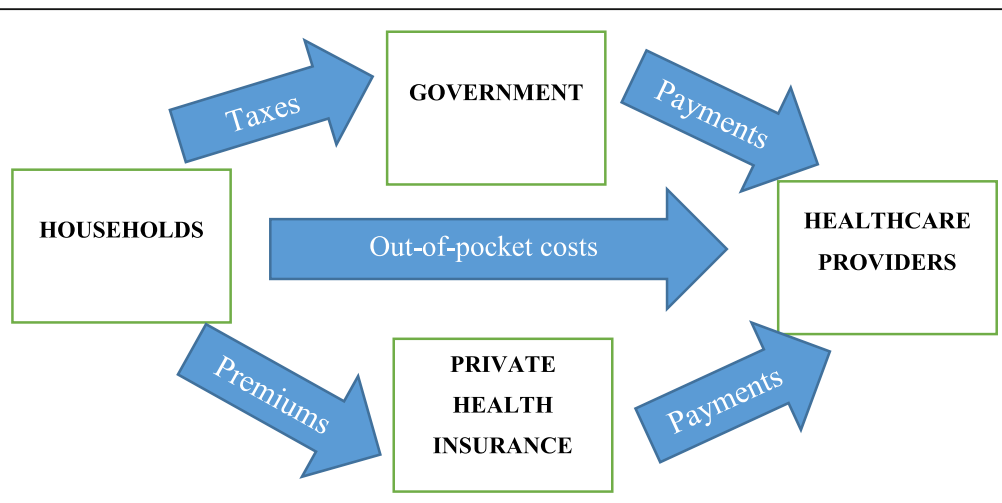

Fig. 1 Flow of health funding in Australian health sector. Source: Duckett and Willcox (2015) 


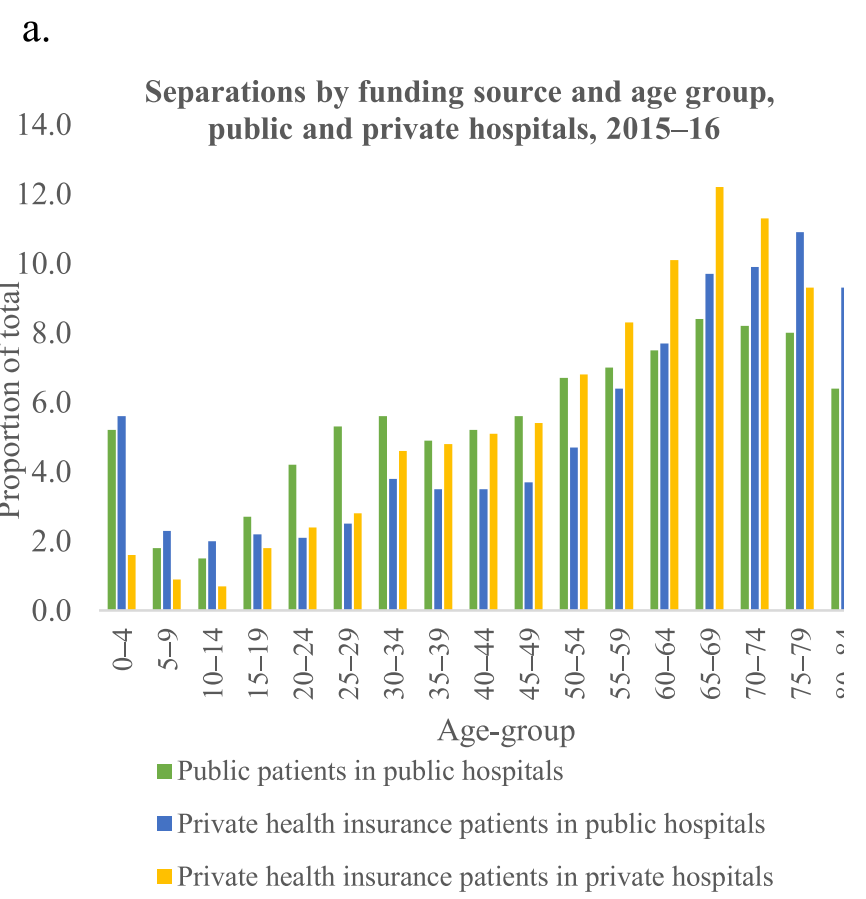

b.

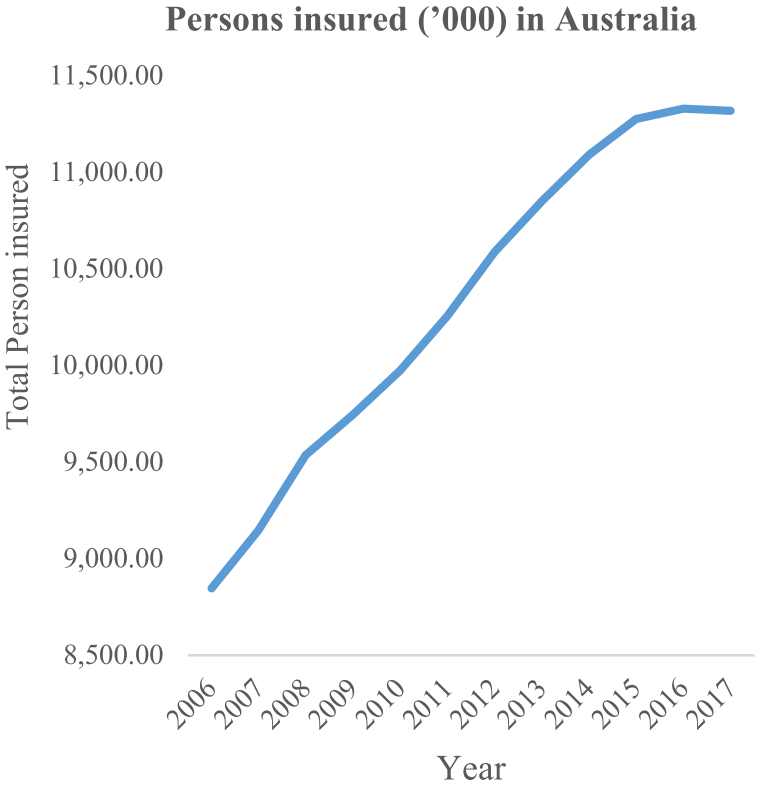

Fig. 2 Trends in the number of persons insured and choice of hospital care in Australia. Source: AlHW (2018). Australian Institute of Health and Welfare. Data available from: https://www.aihw.gov.au/reports/hospitals/private-health-insurance-use-hospitals/data

health services is unique in nature (which depends on individuals' stock of health and their health problems), it is assumed to be a normal good, which means that holding other things constant, increasing price decreases the demand for health services [25].

Eldridge et al. [6] showed that in a hypothetical scenario if everyone has PHI cover, it reduces the effective price of private healthcare; therefore, the demand for private hospitals will increase, and demand for public hospitals will reduce. This switching of demand from the public to private is logical for a country which does not offer public health insurance for all. However, in Australia, given the existence of Medicare, private health services could be seen as duplicate, complementary and supplementary to public health services [19]. Therefore, the choice of the type of services consumed by patients with PHI cover varies considerably, and increasing the enrolment rate in PHI may not divert demand from the public sector to the private sector at the desired (optimal) level. If the type and quality of services are the same between private and public hospitals, the price elasticity of demand for private hospital services will be high. As services in public hospitals can be consumed at low or no cost, patients will avoid private hospital care even if there is an expectation (not actual) of higher premiums in the future (for utilising private care regularly). The availability of publicly funded health coverage increases the opportunity cost (the relative price $\mathrm{P}_{\mathrm{pt}} / \mathrm{P}_{\mathrm{pb}}$ ) of using privately funded services; hence, a patient will be more inclined to consume public hospital care [24].

The model focuses on the impact of PHI on the utilisation of secondary preventive and primary care, and the type of hospital care choices made while taking into account several compounding variables (e.g. age, income and BMI) which might influence the demand for healthcare services.

The rest of this study is structured as follows. The next section explains the data and method. Section three consists of the results of the study, followed by a detailed discussion of the findings. The final section provides a brief conclusion to the study.

\section{Methods}

\section{Data source and study population}

Data were drawn from the 'Household Income and Labour Dynamics in Australia' (HILDA) survey wave 9 (2009) and wave 13 (2013). HILDA is a nationally representative longitudinal survey collected annually since 2001, by the Melbourne Institute of Applied Economic and Social Research [26]. The survey is conducted in accordance with the ethical guidelines approved by the University of Melbourne [27]. Therefore, additional ethical approvals were not required for the current study. Data are available for approved users from the Department of Social Services. 
Both the selected waves had special additional questions related to the health and personality of respondents. Health-specific questions are only conducted every four years. Only waves 5, 9 and 13 were available (with health-specific questions which were used in this study) when the study was being planned, developed, written and data analysis was conducted.

The total number of persons, in the 7234 responding households in 2009 were 17,632 and from 7463 responding households in 2013 were 23,299 individuals [28]. Data were collected via face-to-face interviews and through a self-completed questionnaire from each household. The detailed methodology of the HILDA survey is outlined in [29]. Along with the general survey data, the health-focused waves of 2009 and 2013 accumulated data on healthcare utilisation (GP and hospital visits), general health and well-being (self-assessed health), lifestyle (physical activity, smoking), the prevalence of chronic disease and PHI status. A person with PHI cover was identified with the following question, 'apart from Medicare, are you currently covered by private health insurance?' A total of 13,244 (after excluding missing values) individuals (yes $=7001$, no $=6243$ ) had valid responses in 2009 and for 2013 the total number of valid responses were 17,425 (after excluding missing values) (yes $=9676$, no $=7749$ ).

\section{Variable selections and measures}

A brief description of variable definition, types and measurements is presented in Table 1. Two key independent variables were identified: the PHI status of an individual and their choice of hospital admission type. For the logistic regression, the dependent variable is measured as follows (for a respondent with PHI cover): hospital admission type $=1$ if a public patient in a public hospital and 0 otherwise. In the survey, respondents with current PHI cover were also questioned regarding the type of PHI cover purchased. There are three types of cover; hospital only (covers for the cost of treatments as private patients at the hospitals), ancillary/extras only (covers the cost of services outside of hospitals such as a psychologist) or both. Also, individuals with PHI and who had an overnight hospital stay in the previous 12 months were asked about the 'hospital overnight admission type'. Individuals had to choose from three options; i) public (Medicare) patient in a public hospital, ii) private patient in a private hospital, iii) private patient in a public hospital. For simplification of the analysis a binary variable (hospital admission type) was created where a person with PHI and selected to be a public patient (treated as a patient without PHI) in a public hospital was coded as 1 and 0 otherwise (private patient in a public hospital or private patient in a private hospital).
Several additional variables were used to examine variations in healthcare utilisation between respondents with and without PHI cover. These include the number of doctor visits, number of hospital admissions, and the number of nights stay per hospital admission. Other variables included were whether during the last 12 months respondents had visited a hospital doctor, a specialist doctor or a mental health professional and whether they had health check-ups for breast, prostate or bowel cancer screening, cholesterol or blood pressure during this period. These were also designated as binary variables (yes $=1$, no $=0$ ). The level of preventive care utilisation was measured using screening for pap smear, breast cancer, prostate cancer, bowel cancer and cholesterol provided by insured adults in the previous 12 months [30].

Household annual expenditure on pharmaceuticals and fees paid to health practitioners were used to measure out-of-pocket health expenditure. To understand the current state of an individual's health, three variables were included. Self-assessed health used a Likert scale in five categories (excellent, very good, good, fair and poor) and prevalence of long-term health conditions (yes $=1$, no $=0)$ and mental health status was measured with the Kessler psychological distress scale (low, moderate, high and very high) [31]. Lifestyle variables consisted of physical activity (less than once a week, 1-3 times a week, more than three times per week) and smoking status (non-smoker, occasional smoker, regular smoker). Health shocks (illness) or financial distress can influence the choice of healthcare utilisation [32, 33]. Therefore, health shocks and financial distress were measured thus: serious personal illness (yes $=1$, no $=0$ ) and major worsening in finances (yes $=1$, no $=0$ ), either of these in the last twelve months.

Other key variables that have a confounding influence on health and healthcare utilisation such as age, gender, education, income, body mass index (BMI), marital status, remoteness from hospital and birthplace were also utilised $[6,17,34]$. The age range of the respondent population was 15 to 101, and they were divided into three groups (age $<45$; age $45-65$; age $>65$ ), education level was divided into two categories ( $>$ High school; $\leq$ High school). Furthermore, two subgroups were created for marital status (currently married and all other situations), four groups for BMI and remoteness was calculated using the variable 'section of the state' based on the guidelines of the Australian Bureau of Statistics [35]. Moreover, Booth-Kewley and Vickers [36] concluded that personality is a key determinant of health behaviour. To add to the previous literature, this study examined whether financial risk-taking behaviour (a measure of personality) impacts the healthcare-seeking attitude of individuals with PHI cover (never takes financial risk, takes average financial risks and takes sizeable financial 
Table 1 Variable definition

\begin{tabular}{lll}
\hline Variable & $\begin{array}{l}\text { Variable Measurement } \\
\text { type }\end{array}$ \\
\hline
\end{tabular}

\section{Independent variables (Logistic regression)}

For respondents with PHI: Hospital Binary admission type

For respondents with $\mathrm{PHI}$ : Who had an Binary overnight hospital stay

\section{Other explanatory variables}

Number of doctor visits Number of hospital admissions Number of nights per hospital admission

Whether during the last 12 months, respondents had:

Visited a hospital doctor

Visited a specialist doctor

Visited a mental health professional

Health check-ups or screening

Household annual expenditure on pharmaceuticals

Fees paid to health practitioners

Household disposable income (DY)

Age

Education level

Body Mass Index (BMI)

Self-assessed health

Prevalence of long-term health conditions

Marital status

Mental health status

Physical activity

Smoking status

(Smokes cigarettes or other tobacco products)

Health shocks

(Serious personal illness in the last 12 months)

Financial distress

(Major worsening of finances)

Financial risk-taking attitude

Remoteness

Full time students
1 if a public patient in a public hospital and 0 otherwise

Selected to be a public patient (treated as a patient without PHI) in a public hospital was coded as 1 and 0 otherwise (private patient in a public hospital or private patient in a public hospital).

Continuous Positive values from 0 to upwards.

Binary $\quad$ Yes $=1$
No $=0$

Continuous Positive values from 0 to upwards.

Ordinal Four categories: Low income is $D Y<\$ 63,746$, lower middle income is DY $=\$ 63,746$ to $\$ 100$, 757 , higher middle income is $\$ 100,758$ to $\$ 144,848$ and high income is DY $>\$ 144,849$. Calculated based on the income level of the respondents of the respective waves.

Ordinal Three categories: age < 45; age 45-65; age $>65$.

Binary Two categories: $>$ High school; $\leq$ High school.

Ordinal Four categories based on the respondents BMI: $\mathrm{BMI}=<18.5 ; \mathrm{BMI} 18.6-24.9 ; \mathrm{BMI} 25-29.9 \mathrm{BMI}=>30$.

Scale $\quad$ Five categories (excellent, very good, good, fair and poor) using scale 1-5.

Binary $\quad$ Yes $=1$

$\mathrm{No}=0$

Binary Two categories: Currently married $=1$ and all other situation $=0$.

Scale Kessler psychological distress scale (low, moderate, high and very high) using values 1-4.

Ordinal Three categories: less than once a week, 1-3 times a week, more than three times per week.

Ordinal Three categories: non-smoker $=$ I have never or no longer smoke; regular smoker $=$ Yes, I smoke; occasional smoker = all other answers.

Binary $\quad$ Yes $=1$

$\mathrm{No}=0$

Binary $\quad$ Yes $=1$

No $=0$

Ordinal Three categories: never takes risk, takes average risks and takes sizeable risks.

Binary Two categories:

Urban and rural.

Using 'ASGC 2001 Section of State' variable in the HILDA data as suggested by the Australian Bureau of Statistics.

Binary $\quad$ Yes $=1$ risks). Lastly, a dummy variable for full-time students was used to estimate whether not being part of the labour force had an effect on the selection of healthcare services.

\section{Statistical analysis}

Four types of statistical analyses were performed. First, unadjusted descriptive analyses were conducted to estimate the heterogeneity in the type of hospital care and 
preventive care utilisation based on PHI status. Respondents with PHI cover were further categorised into the three types. Second, repeated measure t-tests were performed for selected sub-groups of participants to examine whether a change in PHI status significantly impacts healthcare utilisation. Using the 'xwaveid' indication in the data, a cohort of people were selected who were common to both waves. Next, a sub-group of 193 respondents were identified who had PHI cover in 2009 but had dropped it in 2013. Then, the repeated measure $\mathrm{t}$-tests were used to compare the healthcare utilisation of this sub-group. Third, Pearson's Chi-square test was used to compare whether the choice of hospital service varied depending on the socioeconomic, demographic, health status and lifestyle characteristics of patients in both waves. Finally, logistic regression was employed to determine the factors influencing hospital choice by different types of patients. This approach is commonly used $[37,38]$ to predict a categorical (mainly dichotomous) variable with a mix of continuous and categorical predictor variables $[37,39]$. The regression model here predicts the probability of admission as a public patient whilst holding PHI cover. The estimation was performed with patients with PHI cover and who had overnight hospital admissions in 2013. The following binary logistic regression model was used:

$$
\log \frac{Y_{p}}{\left(1-Y_{p}\right)}=a_{0}+\sum_{n=1}^{q}\left(\beta_{n} x_{p n}\right)+u_{p}
$$

where $\mathrm{Y}$ is the binary dependent variable and $Y_{p}$ is the probability of a patient with $\mathrm{PHI}$ cover choosing the option of being a public patient in a public hospital. $x_{p n}$ are the predictor variables for $p^{\text {th }}$ observations, $\beta_{n}$ are the estimated coefficients and $u_{p}$ indicates error-terms.

Tests statistics were calculated using bootstrap methods based on 1000 draws, which reduce biases from lack of normality and homoscedasticity $[39,40]$.

For a robustness check, regression analysis was conducted adding state dummies (Australian Capital Territory as the reference category) in the model to control for potential state-wise variations in PHI policies, systems and practices.

\section{Results}

PHI status and healthcare utilisation

Table 2 shows the percentage of respondents who used different types of hospital care and had health check-ups (secondary preventive care) between 2009 and 2013. Overall, around $75 \%$ of patients with $\mathrm{PHI}$ cover selected the private patient option, and the rest consumed public hospital services as a public patient. Hence, almost a quarter of the respondents preferred publicly funded services despite having PHI cover. Conversely, around 7 to 9\% of patients without PHI cover preferred to be a private hospital patient. As expected, there are significant differences in the type of hospital care consumed for patients with only ancillary/extras cover and those with a hospital cover. Patients with PHI preferring public patient care and no cover patients preferring private care

Table 2 Public vs private care utilisation by health insurance status, type of cover and membership (\%)

\begin{tabular}{|c|c|c|c|c|c|c|c|c|}
\hline & $\begin{array}{l}\text { Public patient in } \\
\text { public hospital }\end{array}$ & $\begin{array}{l}\text { Private patient in } \\
\text { private hospital }\end{array}$ & $\begin{array}{l}\text { Private patient } \\
\text { in public } \\
\text { hospital }\end{array}$ & $\begin{array}{l}\text { Health check-up } \\
\text { in last } 12 \text { months }\end{array}$ & $\begin{array}{l}\text { Public } \\
\text { patient } \\
\text { in } \\
\text { public } \\
\text { hospital }\end{array}$ & $\begin{array}{l}\text { Private patient in } \\
\text { private hospital }\end{array}$ & $\begin{array}{l}\text { Private patient } \\
\text { in public } \\
\text { hospital }\end{array}$ & $\begin{array}{l}\text { Health check-up } \\
\text { in last } 12 \text { months }\end{array}$ \\
\hline$\overline{Y E A R}$ & 2009 & & & & 2013 & & & \\
\hline \multicolumn{9}{|l|}{ PHI status } \\
\hline Yes & 25.3 & 58.0 & 16.4 & 75.2 & 22.7 & 59.9 & 17.8 & 75.7 \\
\hline No & 90.7 & 6.7 & 2.3 & 67.6 & 92.8 & 4.9 & 2.1 & 68.6 \\
\hline \multicolumn{9}{|c|}{ PHI cover type } \\
\hline $\begin{array}{l}\text { Hospital } \\
\text { only }\end{array}$ & 26.3 & 56.1 & 17.5 & 77.0 & 21.7 & 59.0 & 19.4 & 78.5 \\
\hline $\begin{array}{l}\text { Extras } \\
\text { only }\end{array}$ & 91.9 & 6.5 & 1.6 & 74.6 & 90.5 & 3.2 & 6.3 & 68.8 \\
\hline Both & 18.9 & 63.3 & 17.6 & 75.4 & 18.3 & 63.1 & 18.5 & 76.3 \\
\hline \multicolumn{9}{|c|}{ Membership type } \\
\hline Family & 25.2 & 60.0 & 14.6 & 69.8 & 24.3 & 59.7 & 15.9 & 70.0 \\
\hline Couple & 19.8 & 62.1 & 18.1 & 87.2 & 18.8 & 60.4 & 20.8 & 87.1 \\
\hline Single & 29.1 & 53.0 & 17.8 & 78.3 & 22.3 & 59.1 & 18.4 & 78.3 \\
\hline
\end{tabular}

Note: Values in percentage. 2009 and 2013 are data from Wave 9 and Wave 13, respectively. Services used in the last 12 months prior to the date interviewed. Public patient in public hospital means a person with no PHI using public hospital services; private patient in private hospital means a person with PHI using private hospital services; private patient in public hospital means a person with $\mathrm{PHI}$ using public hospital services 
reduced by 3 and $2 \%$, respectively, but the rate of health check-ups remained the same between the two waves.

Table 3 presents data on healthcare use and health screening by respondents with PHI cover (excluding ancillary cover only) and no cover from 2009 and 2013. On average, patients with PHI cover had slightly longer overnight stays (1.82 vs 1.74 in 2009 and 1.85 vs 1.76 in 2013, $p<0.05$ ) despite having a significantly lower number of hospital admissions and doctor visits than those with no cover. Having PHI cover is also significantly related to a higher number of specialist doctor visits $(0.51$ vs 0.48 in 2009 and 0.52 vs 0.47 in 2013, $p<0.05$ ). Noticeably, respondents with PHI cover reported a higher level of health screening (e.g. Breast screening: 0.21 vs 0.14 in 2009 and 0.20 vs 0.14 in 2013, p<0.05) compared to no cover respondents, and the mean differences are significant at a $95 \%$ confidence interval.

\section{Effect of dropping PHI cover}

Table 4 reports a brief comparison on individual health status and healthcare utilisation before and after dropping PHI cover. The cohort of 193 respondents had PHI cover in 2009 but discontinued it by the time they were interviewed in 2013. The repeated measure t-test results indicate that except for health screening (e.g. Breast cancer: 0.20 vs $0.09, \mathrm{p}<0.05)$, the mean number of doctor visits (4.6 vs 5.25$)$, hospital admissions ( 0.11 vs 0.19 ) and nights' stay at the hospital ( 0.34 vs 0.79$)$ did not vary significantly before and after dropping PHI cover. Interestingly, self-assessed health $(2.39$ vs $2.62, p<0.05)$ was significantly lower in 2009 compared to 2013, but there was no significant difference in satisfaction with health (7.52 vs 7.21). Lastly, consistent with the findings of
Table 2, this cohort of respondents had, on average, a lower number of specialist doctor visits (0.42 vs 0.37 ), but a higher number of hospital doctor visits ( 0.27 vs 0.31) after dropping their PHI cover. However, the results were not statistically significant.

\section{Patient background and choice of hospital care}

In Table 5, a comparison between the type of hospital care consumed by patients with PHI cover based on their socioeconomic, demographic and lifestyle characteristics is presented. The outcomes of Pearson's Chisquare tests illustrate that the choice of hospital admission type varies significantly between groups based on age, gender, income levels, and marital status. According to the estimated results of both 2009 and 2013, individuals aged 65 or more ( 84 among age $>65$ vs 67.5 among age $<45$ in 2013, $p<0.05$ ), from high-income households (annual income $>\$ 144,849$ ), or those who are currently married $(80.4 \%$ among married vs $72.5 \%$ among all other in 2013, p < 0.05 ) were more likely to opt for the private patient option. Moreover, the results of 2013 also indicate that females (25.1 vs $18.8, \mathrm{p}<0.05)$, patients with BMI lower than 25 (29.3 vs 20.9, p < 0.05), patients without long-term health conditions (25.9 vs 19.1, $\mathrm{p}<0.05$ ), smokers (31.5 vs $21.4, P<0.05$ ), patients with higher than average risk-taking attitude (46.2 vs 25.4, $\mathrm{p}<0.05$ ), and patients in South Australia were more likely to select public patient care compared to males, patients with higher BMI $(>30)$, those with longterm health conditions, non-smokers, lower risk-taking attitude and patients in other states, respectively. Experiencing serious personal illness ( 15.1 vs $11.7, \mathrm{p}<0.05)$ or

Table 3 Differences in healthcare use between individuals with $\mathrm{PHI}$ and no PHI

\begin{tabular}{|c|c|c|c|c|}
\hline \multirow{2}{*}{$\begin{array}{l}\text { Variables } \\
\text { Healthcare use (last } 12 \text { months) } \\
\end{array}$} & \multicolumn{2}{|l|}{2009} & \multicolumn{2}{|l|}{2013} \\
\hline & Cover & No cover & Cover & No cover \\
\hline Number of doctor visits & $5.63^{\mathrm{a}}(.102)$ & $8.51(.187)$ & $5.55^{\mathrm{a}}(.081)$ & $8.54(.163)$ \\
\hline Number of hospital admissions & $0.26^{\mathrm{a}}(.010)$ & $0.45(.028)$ & $0.28^{\mathrm{a}}(.011)$ & $0.50(.049)$ \\
\hline Patient in a hospital overnight & $1.82^{\mathrm{a}}(.006)$ & $1.74(.008)$ & $1.85^{\mathrm{a}}(.005)$ & $1.76(.007)$ \\
\hline Specialist doctor visits & $0.51^{\mathrm{a}}(.008)$ & $0.48(.009)$ & $0.52^{\mathrm{a}}(.006)$ & $0.47(.008)$ \\
\hline Mental health professional & $0.08^{\mathrm{a}}(.004)$ & $0.11(.006)$ & $0.10^{\mathrm{a}}(.004)$ & $0.15(.006)$ \\
\hline \multicolumn{5}{|l|}{ Health screening } \\
\hline Pap smear & $0.29^{\mathrm{a}}(.006)$ & $0.25(.008)$ & $0.28^{\mathrm{a}}(.006)$ & $0.24(.007)$ \\
\hline Breast screening & $0.21^{\mathrm{a}}(.007)$ & $0.14(.006)$ & $0.20^{\mathrm{a}}(.005)$ & $0.14(.006)$ \\
\hline Prostate check & $0.16^{\mathrm{a}}(.006)$ & $0.12(.006)$ & $0.14^{\mathrm{a}}(.005)$ & $0.12(.005)$ \\
\hline Screening for bowel cancer & $0.16^{\mathrm{a}}(.006)$ & $0.12(.006)$ & $0.17^{\mathrm{a}}(.005)$ & $0.13(.006)$ \\
\hline $\mathrm{X}$-rays & $0.25^{\mathrm{a}}(.007)$ & $0.32(.007)$ & $0.26^{\mathrm{a}}(.006)$ & $0.32(.008)$ \\
\hline Blood pressure & $0.75(.007)$ & $0.75(.007)$ & $0.77(.005)$ & $0.76(.007)$ \\
\hline Cholesterol test & $0.52^{\mathrm{a}}(.008)$ & $0.45(.009)$ & $0.52^{\mathrm{a}}(.006)$ & $0.48(.008)$ \\
\hline
\end{tabular}

Notes: Respondents with cover $=5263$ and without cover $=4215$ in 2009 and with cover $=5915$ and without cover $=3739$ in 2013 . Values in percentage of total responded population. ${ }^{a}$ means the mean difference is significant at the $95 \%$ confidence interval 
Table 4 Healthcare utilisation (sub group) before and after dropping private health cover

\begin{tabular}{|c|c|c|c|c|}
\hline Healthcare utilisation & Obs & $\begin{array}{l}\text { Mean } \\
2009\end{array}$ & $\begin{array}{l}\text { Mean } \\
2013\end{array}$ & $\begin{array}{l}\mathrm{p}- \\
\text { value }\end{array}$ \\
\hline $\begin{array}{l}\text { Self-assessed health } \\
(1=\text { excellent; } 2 \text { = very good; } 3=\text { good; } \\
4=\text { fair } 5=\text { =oor })\end{array}$ & 193 & $2.39(0.07)$ & $2.62(0.08)$ & 0.034 \\
\hline $\begin{array}{l}\text { Satisfaction }- \text { Your health } \\
(0=\text { totally dissatisfied; } 5=\text { indifferent; } \\
10=\text { totally satisfied })\end{array}$ & 192 & $7.52(0.12)$ & $7.21(0.13)$ & 0.086 \\
\hline Household annual expenditure - Fees paid to health practitioners & 193 & $880.9(95)$ & $\begin{array}{l}679.9 \\
(111)\end{array}$ & 0.171 \\
\hline Household annual expenditure - Medicines, prescriptions, pharmaceuticals & 193 & $\begin{array}{l}400.6 \\
(33.8)\end{array}$ & $361.9(36)$ & 0.436 \\
\hline $\begin{array}{l}\text { For most recent doctor visit - any out of pocket expenses for consultation } \\
(1=\text { yes; } 2=\text { no })\end{array}$ & 160 & $1.53(0.04)$ & $1.69(0.04)$ & 0.002 \\
\hline Number of doctor visits & 192 & $4.6(0.44)$ & $5.25(0.61)$ & 0.390 \\
\hline Number of hospital admissions & 192 & $0.11(0.03)$ & $0.19(0.04)$ & 0.110 \\
\hline Number of nights in hospital & 192 & $0.34(0.11)$ & $0.79(0.21)$ & 0.063 \\
\hline Number of times have you seen your family doctor or GP in the last 12 months & 160 & $5.36(0.5)$ & $6.30(0.7)$ & 0.273 \\
\hline $\begin{array}{l}\text { Seen during last } 12 \text { months - A hospital doctor (i.e., in outpatients or casualty) } \\
(0=\text { no; } 1=\text { yes) }\end{array}$ & 126 & $0.27(0.04)$ & $0.31(0.04)$ & 0.465 \\
\hline $\begin{array}{l}\text { Seen during last } 12 \text { months - A specialist doctor (excluding in outpatients or casualty of a hospital) }(0=\text { no; } \\
1=\text { yes) }\end{array}$ & 126 & $0.42(0.04)$ & $0.37(0.04)$ & 0.473 \\
\hline Seen during last 12 months $-A$ mental health professional $(0=$ no; $1=$ yes $)$ & 126 & $0.10(0.03)$ & $0.19(0.03)$ & 0.048 \\
\hline $\begin{array}{l}\text { During the last } 12 \text { months, have you ever been a patient in a hospital overnight? } \\
(1=\text { yes; } 2=\text { no })\end{array}$ & 192 & $1.91(0.02)$ & $1.85(0.03)$ & 0.081 \\
\hline Had check-up or test in last 12 months - Breast screening ( $0=$ no; $1=$ yes) & 137 & $0.20(0.04)$ & $0.09(0.03)$ & 0.016 \\
\hline Had check-up or test in last 12 months - Prostate check $(0=$ no; $1=$ yes $)$ & 137 & $0.09(0.02)$ & $0.07(0.02)$ & 0.656 \\
\hline Had check-up or test in last 12 months - for bowel cancer ( $0=$ no; $1=$ yes) & 137 & $0.06(0.02)$ & $0.12(0.03)$ & 0.099 \\
\hline Had check-up or test in last 12 months - Cholesterol test $(0=$ no; $1=$ yes $)$ & 137 & $0.37(0.04)$ & $0.44(0.04)$ & 0.000 \\
\hline Had check-up or test in last 12 months - Blood pressure $(0=$ no; $1=$ yes $)$ & 137 & $0.62(0.04)$ & $0.67(0.04)$ & 0.082 \\
\hline
\end{tabular}

Obs $=$ number of observations. Standard errors in parenthesis

financial distress $(26.2$ vs $11.9, \mathrm{p}<0.05)$ also influences patients' choices of hospital care significantly.

Lastly, patients with PHI in 2013 were less likely to choose public hospital care irrespective of income, education, birth origin, gender, marital status and area of residence than patients in 2009. Moreover, the percentage of patients (with PHI) selecting public care reduced considerably across all states from 2009 to 2013 except for South Australia.

\section{Determinants of the selection of hospital care}

The results of the logistic regression model are presented in Table 6. The factors that influence the probability of selecting public hospital care for respondents with PHI cover from 2013 are shown. The reference category for each variable is in parenthesis.

After adjusting for socioeconomic and demographic characteristics and other key factors, this study found that income level, age, level of education, type of health insurance coverage and type of doctor visits have a significant impact on the selection of hospital care.
According to the findings, young patients $($ age $<45)$ are 2.2 times more likely to select public care compared to older patients (age $>65$ ). In addition, patients from lower-income (income $\leq \$ 100,757$ ) households are 1.4 to 1.8 times more likely to choose public patient care compared to patients from higher-income households (income $>\$ 144,849)$. Conversely, patients with higher education levels (> high school) are $1.56(1 / 0.64)$ times less likely (odds ratio $=0.640, p<0.05$ ) to opt for public patient care in comparison to a patient with lower education levels. Similarly, patients with hospital doctor visits have a lower probability of choosing public patient care (odds ratio $=0.567, \mathrm{p}<0.05$ ). However, patients with higher specialist doctor visits have a $76.55 \%$ higher probability of selecting public patient care (the probability has been calculated using the following formula: $\operatorname{Pr}$ $\left(\mathrm{Y}_{\mathrm{p}}>0\right)=$ odds ratio $/ 1$ +odds ratio). Lastly, patients with higher risk-taking attitudes tend to choose public care (1.2 to 1.4 times more) over private care in comparison to patients with lower risk-taking attitudes. All these results are significant at a $95 \%$ confidence interval. 
Table 5 Pearson's chi square test (public patient vs private patient type admission) for respondents with private health cover

\begin{tabular}{|c|c|c|c|c|c|c|c|c|}
\hline Factors & $\begin{array}{l}\text { Valid } \\
\text { cases }\end{array}$ & $\begin{array}{l}\text { Private patients (in Public } \\
\text { \& Private hospital) }\end{array}$ & $\begin{array}{l}\text { Public patient in a } \\
\text { public hospital }\end{array}$ & $\begin{array}{l}\text { Pearson } \\
\text { Chi-sq }\end{array}$ & $\begin{array}{l}\text { Valid } \\
\text { cases }\end{array}$ & $\begin{array}{l}\text { Private patients (in Public } \\
\text { \& Private hospital) }\end{array}$ & $\begin{array}{l}\text { Public patient in a } \\
\text { public hospital }\end{array}$ & $\begin{array}{l}\text { Pearson } \\
\text { Chi-sq }\end{array}$ \\
\hline & $\underline{2009}$ & & & & $\underline{2013}$ & & & \\
\hline Age & 863 & & & $15.75(0.000)$ & 1196 & & & $41.57(0.000)$ \\
\hline Age $<45$ & & 69.1 & 30.9 & & & 67.5 & 32.5 & \\
\hline Age 45-65 & & 74.6 & 24.5 & & & 83.1 & 16.9 & \\
\hline Age $>65$ & & 83.8 & 16.2 & & & 84.0 & 16.0 & \\
\hline Education level & 863 & & & $1.06(0.170)$ & 1196 & & & $0.70(0.402)$ \\
\hline > High school & & 76.0 & 24.0 & & & 78.6 & 21.4 & \\
\hline$\leq$ High school & & 72.9 & 27.1 & & & 76.5 & 23.5 & \\
\hline Household DY & 863 & & & $10.01(0.018)$ & 1196 & & & $19.92(0.000)$ \\
\hline Low income & & 74.0 & 26.0 & & & 79.2 & 20.8 & \\
\hline Lower middle & & 70.8 & 29.2 & & & 65.9 & 34.1 & \\
\hline Higher middle & & 71.8 & 28.2 & & & 79.0 & 21.0 & \\
\hline High income & & 83.4 & 16.6 & & & 81.0 & 19.0 & \\
\hline Birthplace & 863 & & & $2.42(0.120)$ & 1187 & & & $1.39(0.237)$ \\
\hline Australia & & 75.0 & 25.0 & & & 76.5 & 23.5 & \\
\hline Other country & & 61.5 & 38.5 & & & 80.2 & 19.8 & \\
\hline Gender & 863 & & & $0.88(0.347)$ & 1196 & & & $6.27(0.012)$ \\
\hline Female & & 75.8 & 24.2 & & & 74.9 & 25.1 & \\
\hline Male & & 73.0 & 27.0 & & & 81.2 & 18.8 & \\
\hline Marital status & 863 & & & $8.88(0.003)$ & 1196 & & & $10.01(0.002)$ \\
\hline Currently married & & 78.1 & 21.9 & & & 80.4 & 19.6 & \\
\hline All other situations & & 69.0 & 31.0 & & & 72.5 & 27.5 & \\
\hline BMI & 863 & & & $2.58(0.460)$ & 1196 & & & $10.27(0.016)$ \\
\hline $\mathrm{BMI}=<18.5$ & & 70.6 & 29.4 & & & 70.7 & 29.3 & \\
\hline BMI 18.6-24.9 & & 73.5 & 26.5 & & & 74.7 & 25.3 & \\
\hline BMI 25-29.9 & & 75.4 & 24.6 & & & 81.6 & 18.4 & \\
\hline $\mathrm{BMI}=>30$ & & 78.0 & 22.0 & & & 79.1 & 20.9 & \\
\hline Remoteness & 863 & & & $4.21(0.040)$ & 1196 & & & $0.06(0.805)$ \\
\hline Major city & & 76.9 & 23.1 & & & 77.5 & 22.5 & \\
\hline Other places & & 70.6 & 29.4 & & & 76.8 & 23.2 & \\
\hline Long-term health conditions & 862 & & & $0.52(0.471)$ & 1195 & & & $7.98(0.005)$ \\
\hline No & & 73.6 & 26.4 & & & 74.1 & 25.9 & \\
\hline Yes & & 75.8 & 24.2 & & & 80.9 & 19.1 & \\
\hline Physical activity per week & 764 & & & $6.05(0.048)$ & 1067 & & & $0.52(0.770)$ \\
\hline Less than once & & 73.0 & 27.0 & & & 78.7 & 21.3 & \\
\hline $1-3$ times & & 79.8 & 20.2 & & & 76.5 & 23.5 & \\
\hline More than 3 & & 71.2 & 28.8 & & & 77.1 & 22.9 & \\
\hline Smoking frequency & 860 & & & & 1052 & & & $7.27(0.026)$ \\
\hline Non-smoker & & & & & & 78.6 & 21.4 & \\
\hline Occasional smoker & & & & & & 63.0 & 37.0 & \\
\hline Regular smoker & & & & & & 68.2 & 31.8 & \\
\hline Self-assessed health & 760 & & & $2.04(0.727)$ & 1065 & & & $9.36(0.530)$ \\
\hline Excellent & & 78.8 & 21.2 & & & 63.9 & 36.1 & \\
\hline Very good & & 78.2 & 21.8 & & & 76.6 & 23.4 & \\
\hline Good & & 73.3 & 26.7 & & & 78.0 & 22.0 & \\
\hline Fair & & 74.5 & 25.5 & & & 80.6 & 19.4 & \\
\hline Poor & & 75.9 & 24.1 & & & 80.0 & 20.0 & \\
\hline
\end{tabular}


Table 5 Pearson's chi square test (public patient vs private patient type admission) for respondents with private health cover (Continued)

\begin{tabular}{|c|c|c|c|c|c|c|c|c|}
\hline Factors & $\begin{array}{l}\text { Valid } \\
\text { cases }\end{array}$ & $\begin{array}{l}\text { Private patients (in Public } \\
\text { \& Private hospital) }\end{array}$ & $\begin{array}{l}\text { Public patient in a } \\
\text { public hospital }\end{array}$ & $\begin{array}{l}\text { Pearson } \\
\text { Chi-sq }\end{array}$ & $\begin{array}{l}\text { Valid } \\
\text { cases }\end{array}$ & $\begin{array}{l}\text { Private patients (in Public } \\
\text { \& Private hospital) }\end{array}$ & $\begin{array}{l}\text { Public patient in a } \\
\text { public hospital }\end{array}$ & $\begin{array}{l}\text { Pearson } \\
\text { Chi-sq }\end{array}$ \\
\hline Kessler PDS risk & 768 & & & $6.14(0.105)$ & 1063 & & & $3.29(0.350)$ \\
\hline Low & & 77.6 & 22.4 & & & 79.3 & 20.7 & \\
\hline Moderate & & 73.0 & 27.0 & & & 75.7 & 24.3 & \\
\hline High & & 73.2 & 26.8 & & & 75.0 & 25.0 & \\
\hline Very high & & 61.9 & 38.1 & & & 71.7 & 28.3 & \\
\hline Financial risk-taking attitude & & & & & 1045 & & & $16.04(0.003)$ \\
\hline Never takes risk & & & & & & 74.5 & 25.4 & \\
\hline Takes average risks & & & & & & 86.9 & 13.0 & \\
\hline Takes sizeable risks & & & & & & 53.8 & 46.2 & \\
\hline Full-time student & 863 & & & $0.06(0.806)$ & 1196 & & & $15.31(0.000)$ \\
\hline Yes & & 76.3 & 23.7 & & & 57.1 & 42.1 & \\
\hline No & & 74.5 & 25.5 & & & 78.4 & 21.6 & \\
\hline State & 863 & & & $5.05(0.653)$ & 1196 & & & $17.24(0.016)$ \\
\hline NSW & & 75.6 & 24.4 & & & 79.3 & 20.7 & \\
\hline VIC & & 78.5 & 21.5 & & & 81.9 & 18.1 & \\
\hline QLD & & 72.7 & 27.3 & & & 75.3 & 24.7 & \\
\hline SA & & 69.1 & 30.9 & & & 69.1 & 30.9 & \\
\hline WA & & 74.2 & 25.8 & & & 79.7 & 20.3 & \\
\hline Health shocks & 574 & & & $4.39(0.036)$ & 1054 & & & $12.03(0.001)$ \\
\hline Yes & & 73.2 & 26.8 & & & 84.9 & 15.1 & \\
\hline No & & 80.1 & 19.9 & & & 88.3 & 11.7 & \\
\hline Financial distress & 574 & & & $0.14(0.71)$ & 1065 & & & $35.52(0.000)$ \\
\hline Yes & & 75.2 & 24.8 & & & 73.8 & 26.2 & \\
\hline No & & 77.6 & 22.4 & & & 88.1 & 11.9 & \\
\hline
\end{tabular}

Note: Data from HILDA survey 2009 and 2013. P-values are in the parenthesis. Values in percentage. Here, DY means disposable income. Low income is $\mathrm{DY}<\$ 63,746)$, lower middle income is $\mathrm{DY}=\$ 63,746$ to $\$ 100,757$, higher middle income is $\$ 100,758$ to $\$ 144,848)$ and high income is DY> $\$ 144,849$. The variable financial risk-taking attitude was not available in 2009. Tasmania, Northern Territory and Australian Capital Territory had patient count less than 25 . Hence, these data are not reported in the table. PDS means psychological distress scale. Identical questions regarding smoking habit and financial risk-taking attitude are not available between 2009 and 2013

Although the following results are statistically insignificant, it is important to note that patients who are women (54\%), without long-term health problems (57\%), currently not married (53\%) and from urban areas (55\%) have a higher probability of selecting public care at hospitals compared to patients who are men, with longterm health problems, married and living in rural areas, respectively.

Several diagnostic tests were also conducted, results of which are presented in Table 6 and justify the soundness of the regression model selected. The Omnibus test for model coefficient has $p<0.01$, which indicates that additional explanatory variables improved the accuracy of the model. The Hosmer and Lemeshow test results suggest that the model is a good fit $(p>0.05)$. The $\mathrm{R}$-square values of Cox and Snell test and Nagelkerke test illustrate that the model explains 22.3 and $34.5 \%$ of the variations in the outcome variable, respectively.
The signs and significance of the coefficients were confirmed in the sensitivity analysis (Table 7), further implying the reliability of the model. The results also indicate that patients with PHI in New South Wales (odds ratio $0.366, p<0.05$ ), Victoria (odds ratio $0.270, \mathrm{p}<0.05$ ) and Queensland (odds ratio 0.231, $\mathrm{p}<0.05$ ) are significantly less likely to select public hospital care compared to other states.

\section{Discussion}

This paper provides an estimate of the impact of PHI cover on overall healthcare usage and type of hospital selected among Australian adults using a nationally representative data set. There are significant disparities in secondary preventive care, overnight hospital stay and specialist care utilisations between patients with and without PHI cover. Similar to earlier studies, this study also found that private hospital cover encourages 
patients to consume private care [6, 23, 34]. This behaviour of PHI patients is understandable as individuals treated as private patients have shorter waiting for treatments, the ability to choose their physicians and enjoy better amenities (e.g. private rooms) [3]. Yet, the results also indicate that around one in four adults in Australia with PHI cover prefers to use public care. Finally, the results of the adjusted binary logistic regression model indicate that lower incomes, younger age, lower levels of education, specialist doctor visits and higher risk-taking attitudes increase the probability of choosing public care among patients with PHI cover. Hence, this study concludes that patients from lower socioeconomic status have a higher probability of choosing public care at the hospitals despite having PHI cover. The critical question is, why?

The Private Health Insurance Act (2007) prohibits insurance providers from discriminating on premium prices based on age, gender, race, religion or health status. However, under this mandatory community rating, premiums are allowed to vary based on the extent of the coverage and treatments included $[17,18]$. Young adults are allowed to buy PHI cover while excluding services such as coronary care, joint replacement, cataract surgery and women may decide not to include pregnancy care coverage [41]. People are encouraged to purchase PHI cover due to these exemptions with lower premiums and higher service deductibles along with other "carrot and stick" policies imposed by the government. This explains the findings that people who are younger, female, from low-income households, without long-term health conditions, lower BMI and with higher selfassessed health choose public patient care even though they have PHI cover. Given their comparative goodhealth or lower ability to pay, they have more probability of buying PHI cover with significant service deductibles compared to people without these characteristics [42]. On the other hand, patients (with or without PHI cover) may choose a private hospital to avoid long waiting times at public hospitals. The expectation of longer waiting times is a significant determinant of a patient taking up PHI cover for private care [10]. Hence, it is justifiable that older patients, patients from high-income households, those with long-term health conditions and lower health status choose private care over public care, regardless of their PHI status. Patients with these characteristics often do not wish or cannot wait a significant time for treatment.

It is also important to note that patients often have little say in the decision to choose the type of hospital care. As Ungar and Ariely [43] indicated, private hospitals in Australia often refer complex patient cases to public hospitals. Patients entering a hospital through emergency departments or for emergency services mostly end up being a public patient [44]. Another important aspect is the lack of information regarding the additional outof-pocket costs associated with being a private patient at the hospital. The Senate Community Affairs References Committee (2) concluded that patients with PHI cover using care for chronic illness from the private health system bear higher out-of-pocket costs (than those using public care) and are not adequately informed beforehand of the costs. This lack of information may significantly impact the decision of choice of care at the time of needing care. Henceforth, the aforementioned reasons may explain a patient's decision to use public care.

Similar to previous studies (conducted in other countries), the results indicate that the care choice of patients who suffered life event shocks are different from those without that experience. Findings of these earlier literature $[2,43,44]$ partly explain why patients with PHI cover who experienced health shocks or have immediate financial pressure prefer public care over private care.

The estimated results from the merged data of 2009 and 2013 (a cohort of 193 respondents) showed that respondents dropped their PHI cover despite reporting a significant worsening in their self-assessed health status. The mean numbers of health care utilisation (e.g. hospital admissions and hospital nights) were also lower in 2009 (with PHI cover) than in 2013 (dropped PHI cover). These findings nullify the adverse selection hypothesis (people with higher health risk tend to purchase PHI cover) as overall cover consists of a large pool of individuals with lower health risks. This is due to the policies introduced by the federal government (discussed earlier in the section). These findings are similar to the conclusions of earlier comparable studies [5, 6, 17, 45]. A further analysis indicated that in $2013,74.6 \%$ of the respondents with PHI had no long-term health conditions, $49.2 \%$ were in the age group of 45 or lower, $87.3 \%$ assessed their health as good or higher, $81.8 \%$ had a BMI less than $30,90.3 \%$ were non-smokers, and only $23.9 \%$ did not do regular exercise (results not reported). Hence, the findings are justifiable.

The evidence also shows that individuals who have PHI cover had a significantly higher rate of health check-ups relative to individuals without it. In addition, a significant disparity was observed in the use of specialist care as patients with PHI (ancillary services coverage) have lower or no out-of-pocket costs of seeing a specialist. These findings uphold the concern raised by previous studies that the PHI system in Australia is inequitable as services are not provided to those who require it, but rather to those who have the ability to pay for it $[1,46]$.

Finally, the results also indicate that PHI patients who visited hospital doctors are significantly more likely to choose private care and those who visited specialist 
Table 6 Key determinants of hospital care-seeking behaviour of patients with private insurance cover

\begin{tabular}{|c|c|c|c|c|c|}
\hline Factors (reference category) & Beta & Wald & S.E. & P-value & Odds ratio \\
\hline \multicolumn{6}{|l|}{ Self- assesses health (Poor) } \\
\hline Excellent & 0.039 & 0.005 & 0.572 & 0.942 & 1.039 \\
\hline Very good & -0.267 & 0.360 & 0.460 & 0.527 & 0.766 \\
\hline Good & 0.031 & 0.006 & 0.418 & 0.937 & 1.032 \\
\hline Fair & -0.327 & 0.611 & 0.445 & 0.410 & 0.721 \\
\hline \multicolumn{6}{|l|}{ Household disposable income (High) } \\
\hline Low income & 0.341 & 1.324 & 0.301 & 0.056 & 1.407 \\
\hline Lower-middle income & 0.591 & 4.883 & 0.284 & 0.032 & 1.806 \\
\hline Higher-middle income & -0.353 & 1.718 & 0.29 & 0.195 & 0.703 \\
\hline \multicolumn{6}{|l|}{$\mathrm{BMI}(\mathrm{BMI}=>30)$} \\
\hline $\mathrm{BMI}<=18.5$ & 0.681 & 2.666 & 0.439 & 0.101 & 1.976 \\
\hline BMI 18.6-24.9 & -0.039 & 0.026 & 0.247 & 0.858 & 0.961 \\
\hline BMI 25.29.9 & -0.333 & 1.828 & 0.253 & 0.168 & 0.717 \\
\hline \multicolumn{6}{|l|}{ Age (Age $>65$ ) } \\
\hline Age $<45$ & 0.772 & 6.601 & 0.302 & 0.005 & 2.165 \\
\hline Age $45-65$ & 0.167 & 0.332 & 0.282 & 0.531 & 1.182 \\
\hline \multicolumn{6}{|l|}{ Type of health cover (Both) } \\
\hline Hospital only & 0.195 & 0.506 & 0.275 & 0.463 & 1.215 \\
\hline Extras only & 4.053 & 15.548 & 2.271 & 0.001 & 7.550 \\
\hline \multicolumn{6}{|l|}{ Physical activity (> 3 times a week) } \\
\hline$<$ once a week & 0.119 & 0.233 & 0.255 & 0.629 & 1.127 \\
\hline 1-3 times a week & -0.119 & 0.281 & 0.247 & 0.614 & 0.888 \\
\hline \multicolumn{6}{|l|}{ Financial risk-taking attitude (Never) } \\
\hline Substantial risks & 1.281 & 3.514 & 1.616 & 0.081 & 3.600 \\
\hline Above average risks & 1.56 & 3.924 & 5.956 & 0.04 & 1.210 \\
\hline Average risks & -0.114 & 0.148 & 0.313 & 0.702 & 0.892 \\
\hline Not willing & 0.026 & 0.008 & 0.309 & 0.922 & 1.026 \\
\hline \multicolumn{6}{|l|}{ Other compounding variables } \\
\hline Born outside Australia (In Australia) & -0.352 & 1.878 & 0.267 & 0.163 & 0.704 \\
\hline Female (Male) & 0.175 & 0.722 & 0.21 & 0.39 & 1.191 \\
\hline No long-term health condition (Yes) & 0.295 & 1.63 & 0.245 & 0.201 & 1.343 \\
\hline Not a full-time student (Full-time student) & -0.712 & 3.502 & 0.417 & 0.039 & 0.491 \\
\hline Currently not married (Married) & 0.148 & 0.547 & 0.22 & 0.459 & 1.160 \\
\hline Rural (Urban) & -0.219 & 0.60 & 0.326 & 0.47 & 0.804 \\
\hline Education more than High school (Otherwise) & -0.447 & 4.419 & 0.221 & 0.033 & 0.640 \\
\hline Hospital doctor visit (Otherwise) & -0.567 & 8.415 & 0.209 & 0.002 & 0.567 \\
\hline Specialist doctor visits (Otherwise) & 1.183 & 33.211 & 0.213 & 0.001 & 3.265 \\
\hline \multirow[t]{2}{*}{ Constant } & -1.310 & 3.326 & 0.769 & 0.076 & 0.270 \\
\hline & Chi-sq & & $P$-value & & $R-s q$ \\
\hline Omnibus test model coefficients & 252.78 & & 0.000 & & \\
\hline Hosmer \& Lemeshow & 12.99 & & 0.112 & & \\
\hline-2 Log likelihood ${ }^{a}$ & 790.81 & & & & \\
\hline Cox \& Snell & & & & & 0.223 \\
\hline Nagelkerke & & & & & 0.345 \\
\hline
\end{tabular}

Note: Data from Wave 13. Bootstrap standard errors and p-values. Results are based on 1000 bootstrap samples. Reference category presented in the parenthesis. Dependent variable hospital admission type $=1$ if public patient in a public hospital and 0 otherwise

a estimation terminated at iteration number 0.5 because parameter estimates changed by less than 0.001 
Table 7 Key determinates hospital care-seeking behaviour of patients with private insurance cover (including states)

\begin{tabular}{|c|c|c|c|c|c|}
\hline Factors (reference category) & Beta & Wald & S.E. & P-value & Odds ratio \\
\hline \multicolumn{6}{|l|}{ Self- assesses health (Poor) } \\
\hline Excellent & .199 & .134 & .545 & .715 & 1.220 \\
\hline Very good & -.218 & .229 & .455 & .633 & 0.804 \\
\hline Good & .031 & .008 & .420 & .929 & 1.038 \\
\hline Fair & -.293 & .471 & .426 & .492 & 0.746 \\
\hline \multicolumn{6}{|l|}{ Household disposable income (High) } \\
\hline Low income & .394 & 1.661 & .306 & .197 & 1.483 \\
\hline Lower-middle income & .661 & 5.773 & .275 & .016 & 1.937 \\
\hline Higher-middle income & -.314 & 1.315 & .274 & .251 & 0.730 \\
\hline \multicolumn{6}{|l|}{$\mathrm{BMI}(\mathrm{BMI}=>30)$} \\
\hline $\mathrm{BMI}<=18.5$ & .739 & 2.950 & .430 & .086 & 2.094 \\
\hline BMI 18.6-24.9 & -.024 & .009 & .249 & .923 & 0.976 \\
\hline BMI 25.29.9 & -.353 & 1.980 & .251 & .159 & 0.702 \\
\hline \multicolumn{6}{|l|}{ Age $($ Age $>65)$} \\
\hline Age $<45$ & .768 & 6.258 & .307 & .012 & 2.155 \\
\hline Age $45-65$ & .189 & .411 & .296 & .521 & 1.209 \\
\hline \multicolumn{6}{|l|}{ Type of health cover (Both) } \\
\hline Hospital cover only & .310 & 1.180 & .286 & .277 & 1.364 \\
\hline Extra cover only & 4.098 & 8.360 & .589 & .000 & 6.204 \\
\hline \multicolumn{6}{|l|}{ Physical activity (> 3 times a week) } \\
\hline$<$ once a week & .126 & .249 & .252 & .618 & 1.134 \\
\hline 1-3 times a week & -.159 & .476 & .230 & .490 & 0.853 \\
\hline \multicolumn{6}{|l|}{ Financial risk-taking attitude (Never) } \\
\hline Substantial risks & .867 & 1.605 & .685 & .205 & 2.381 \\
\hline Above average risks & -1.76 & 4.848 & .801 & .028 & 0.171 \\
\hline Average risks & -.196 & .422 & .302 & .516 & 0.822 \\
\hline Not willing & -.095 & .108 & .290 & .742 & 0.909 \\
\hline \multicolumn{6}{|l|}{ Other compounding variables } \\
\hline Born outside Australia (In Australia) & -.469 & 3.213 & .262 & .073 & 0.626 \\
\hline Female (Male) & .136 & .420 & .210 & .517 & 1.145 \\
\hline No long-term health condition (Yes) & .315 & 1.770 & .237 & .183 & 1.370 \\
\hline Not a full-time student (Full-time student) & -.615 & 2.552 & .385 & .110 & 0.541 \\
\hline Currently not married (Married) & .216 & 1.124 & .204 & .289 & 1.241 \\
\hline Rural (Urban) & -.128 & .201 & .285 & .654 & 0.880 \\
\hline Education more than High school (Otherwise) & -.459 & 4.537 & .215 & .033 & 0.632 \\
\hline Hospital doctor visit (Otherwise) & -.556 & 7.830 & .199 & .005 & 0.574 \\
\hline Specialist doctor visits (Otherwise) & 1.238 & 34.843 & .210 & .000 & 3.450 \\
\hline \multicolumn{6}{|l|}{ State (Capital Territory) } \\
\hline New South Wales & -1.01 & 4.874 & .455 & .027 & 0.366 \\
\hline Victoria & -1.46 & 9.572 & .474 & .002 & 0.231 \\
\hline Queensland & -1.31 & 7.490 & .479 & .006 & 0.270 \\
\hline South Australia & -.392 & .592 & .510 & .441 & 0.675 \\
\hline Western Australia & -.940 & 3.538 & .500 & .060 & 0.390 \\
\hline Tasmania & -1.46 & 3.550 & .780 & .060 & 0.230 \\
\hline
\end{tabular}


Table 7 Key determinates hospital care-seeking behaviour of patients with private insurance cover (including states) (Continued)

\begin{tabular}{|c|c|c|c|c|c|}
\hline Factors (reference category) & Beta & Wald & S.E. & P-value & Odds ratio \\
\hline Northern Territory & 0.468 & .248 & .940 & .619 & 1.596 \\
\hline \multirow[t]{2}{*}{ Constant } & -.358 & .187 & .828 & 0.076 & 0.699 \\
\hline & Chi-sq & & P-value & & $R-s q$ \\
\hline Omnibus test model coefficients & 272.462 & & 0.000 & & \\
\hline Hosmer \& Lemeshow & 10.724 & & 0.218 & & \\
\hline-2 Log likelihood ${ }^{a}$ & 771.135 & & & & \\
\hline Cox \& Snell & & & & & 0.24 \\
\hline Nagelkerke & & & & & 0.37 \\
\hline
\end{tabular}

Note: Data from Wave 13. Bootstrap standard errors and p-values. Results are based on 1000 bootstrap samples. Reference category presented in the parenthesis. Dependent variable hospital admission type $=1$ if public patient in a public hospital and 0 otherwise

a estimation terminated at iteration number 0.5 because parameter estimates changed by less than 0.001

doctors have a higher probability of selecting public hospital care. It is difficult to explain these findings from the data, and the answer to these findings are well beyond the scope of this study. Hence, future studies could look into the association between PHI status, specialist and hospital doctor visits and the choice of hospital care in Australia.

Several policy suggestions can be offered based on these results. Firstly, it is evident that PHI cover encourages people to use private care. However, a considerable number of PHI patients are not consuming private care when they are eligible may indicate a lack of coherence in the policy and/or consumer information asymmetry, and perceived higher quality and specialisation of public hospitals compared to private hospitals. Besides, proximity to public hospitals may also influence the decision of the patients. Over time, those with specific characteristics (e.g. young age, better health status or low-income) may discontinue $\mathrm{PHI}$, if they assess that they are paying for it without consuming the associated available private services, and if they do then, out-of-pocket costs are higher (than using public care). This trend is evident from the latest AIHW data (Fig. 2). Secondly, respondents with PHI cover showed a notably higher level of health screening than those without. Nonetheless, the rate of screening is less than $30 \%$. PHI providers should encourage their customers to increase the rate of health screening by offering rebates in premiums or expansion in coverage with similar premiums. This preventive behaviour should generate considerable benefits for the health system (private and public) in the long-run. Thirdly, further studies are required to understand why patients from lower socioeconomic status have more probability of using public care despite having PHI cover. It is most likely the out-of-pocket cost associated with using private care, but that has not been proven conclusively. Fourthly, policymakers should examine methods to reduce the inequality in secondary preventive care and specialist care use between PHI patients and those without cover.
This study has some limitations. Firstly, it is difficult to account for any internal factors or policies that govern the PHI provider premiums and coverage policy. Given that the price elasticity of healthcare demand is non-zero, therefore, changes in prices (PHI premiums) have a significant impact on a patient's decision. Second, the choice between public and private care may be influenced by expectations of the quality of care that will be received and the proximity of a private hospital. This study could not account for these issues. Lastly, since data on the type of disease/illness treated at each hospital for each patient was unavailable, this study could not examine the impact of the type of disease had on the hospital choice decision. On the other hand, the findings indicate that the type of doctor visit significantly influences the hospital choice decision, but it was not clear why. Further studies with primary data are required to understand the relationship between the type of disease, type of doctor visits and choice of hospital care.

\section{Conclusions}

This paper investigated the healthcare use of individuals with or without PHI cover and the determinants of the choice of hospital care (private vs public) of patients with PHI cover. The results indicate that PHI status significantly impacts the use of preventive care, specialist care, and overnight stays at hospitals in Australia. Moreover, patients from lower socioeconomic status (e.g. low income and lower education level) and patients who are relatively young (age $<65$ ), without long-term health conditions, better self-assessed health and had recent experience of serious illness or financial distress have a higher probability of selecting public care at the hospital despite holding PHI cover. Except for specialist care use and the number of hospital night stays, healthcare utilisation did not vary significantly among a cohort of individuals before and after dropping PHI cover. These results are important inputs into policy discussions to 
enable a more equitable health system, which ensures equal access to care services based on necessity rather than the ability to pay.

\section{Abbreviations}

AlHW: Australian Institute of Health and Welfare; BMI: Body Mass Index; GDP: Gross Domestic Product; GP: General Practitioner; HILDA: Household Income and Labour Dynamics in Australia; OECD: Organisation for Economic Co-Operation and Development; PHI: Private Health Insurance; Pr: Probability

\section{Acknowledgements}

Not applicable.

\section{Declarations}

The authors of this study declare the following

\section{Authors' contribution}

RHR designed the study, conducted statistical analysis and prepared the initial draft of the manuscript. KA assisted in designing the study, supervised data analysis and the writing of the manuscript. JG updated the research design and reviewed the article. All authors read and approved the final manuscript.

\section{Author information}

Dr Rezwanul H. Rana has completed his PhD in the School of Commerce at the University of Southern Queensland. He holds an MA in Economics from Middlesex University, UK. He has published numerous research papers in quartile one journals. Rezwanul's current research focusses on health economics, in particular, economic burden non-communicable diseases and ageing. His research interests also include rising healthcare expenditure and inequality in healthcare access and utilisation in developed and developing countries. Rezwanul is currently working on two health related projects and has several research papers under the revision stage in quartile one journals. Dr Khorshed Alam is a Professor of Economics in the School of Commerce at the University of Southern Queensland (USO), Australia. His recent research interests encompass health economics and policy issues. Prof Alam has received funding through federal, state and local government agencies in Australia. Currently, he is leading a health economics and policy program at the Centre for Health Research, USO

Dr Jeff Gow is a Professor of Economics in the School of Commerce at the University of Southern Queensland, Toowoomba, Australia. He is also a Research Associate of the School of Accounting, Economics and Finance, University of KwaZulu-Natal, Durban, South Africa and a Professor Extraordinaire in the Department of Agricultural Economics, Stellenbosch University, Stellenbosch, South Africa. His research interests encompass health economics, especially HIV/AIDS globally, and Australian agricultural economics and international wine economics.

\section{Funding}

Not applicable.

\section{Availability of data and materials}

The sources of the data are:

This research program prepares and analyses data drawn from the Household, Income and Labour Dynamics in Australia Survey, known as HILDA

Data are available for approved users from the Department of Social Services, Government of Australia. The survey was carried out in accordance with the ethical guidelines approved by University of Melbourne. Details of the data are available at: https://melbourneinstitute.unimelb.edu.au/research-programs/householdincome-and-labour-dynamics How to use the HILDA data (user manual): Summerfield, M., Freidin, S., Hahn, M., La, N, Li, N., Macalalad, N., O'Shea, M. Watson, N., Wilkins, R. and Wooden, M. (2016), 'HILDA User Manual - Release 15', Melbourne Institute of Applied Economic and Social Research, University of Melbourne.

\section{Ethics approval and consent to participate}

Not applicable as the study was conducted using secondary data from the 'Household, Income and Labour Dynamics in Australia (HILDA) survey database (Wave 9 and 13). This nationally representative longitudinal survey is conducted each year since 2001 by the 'Melbourne Institute of Applied Economic and Social Research' and accessible via the 'Australian Data Archive'. Therefore, this article does not contain any studies with human participants performed by any of the authors.

\section{Consent for publication}

All authors consent to the publication of the manuscript in BMC Health Services Research. No additional consent is required.

\section{Competing interests}

The authors declare that they have no competing interest.

\section{Author details}

'School of Commerce, University of Southern Queensland, Toowoomba, Australia. ${ }^{2}$ School of Commerce, Centre for Health Research, University of Southern Queensland, Toowoomba, Australia. ${ }^{3}$ School of Accounting, Economics and Finance, University of KwaZulu-Natal, Durban, South Africa.

Received: 28 May 2019 Accepted: 26 April 2020

Published online: 06 May 2020

\section{References}

1. Podger A. Federalism and Australia's national health and health insurance system. Asia Pacific Journal of Health Management. 2016;11(3):26.

2. Senate Community Affairs References Committee. In: The Senate Community Affairs Committee Secretariat, editor. Out-of-pocket costs in Australian healthcare. Canberra: Commonwealth of Australia; 2014. p. 2014

3. Buchmueller T, Fiebig DG, Jones G, Savage E. Preference heterogeneity and selection in private health insurance: the case of Australia. J Health Econ. 2013:32(5):757-67

4. Barros PP, Siciliani L. Public and private sector interface. In: Pauly MV, McGuire TG, Barros PP, editors. Handbook of Health Economics, vol. 2. Elsevier; 2011. p. 927-1001. https://doi.org/10.1016/B978-0-444-53592-4. 00015-3.a.

5. Barrett GF, Conlon R. Adverse selection and the decline in private health insurance coverage in Australia: 1989-95. Econ Rec. 2003:79(246):279-96.

6. Eldridge DS, Onur I, Velamuri M. The impact of private hospital insurance on the utilization of hospital care in Australia. Appl Econ. 2017:49(1):78-95.

7. Srivastava $P$, Chen $G$, Harris A. Oral health, dental insurance and dental service use in Australia. Health Econ. 2017;26(1):35-53.

8. Frech $\mathrm{H}$ III, Hopkins S. Why subsidise private health insurance? Aust Econ Rev. 2004;37(3):243-56

9. Cheng TC, Vahid F. Demand for hospital care and private health insurance in a mixed public-private system: empirical evidence using a simultaneous equation modeling approach. HEDG Working Paper 10/25 2011.

10. Dixit SK, Sambasivan M. A review of the Australian healthcare system: a policy perspective. SAGE Open Med. 2018:6:1-14.

11. Hall J. Australian health care-the challenge of reform in a fragmented system. N Engl J Med. 2015:373(6):493-7.

12. Australian Institute of Health and Welfare. Australia's health 2014. Cat. no. AUS 178. Canberra: AlHW; 2014. Available from https://www.aihw.gov.au/ getmedia/d2946c3e-9b94-413c-898c-aa5219903b8c/16507.pdf.aspx?inline= true. Accessed 20 Jan 2020

13. OECD. Organisation for economic co-operation and development health statitics. Paris; 2019. Available from: https://www.oecd.org/health/healthdata.htm

14. Calder R, Dunkin R, Rochford C, Nichols T. Australian health services: too complex to navigate: a review of the national reviews of Australia's health service arrangements, Victoria University, policy issues paper ISBN 0-64826 21-3-8; 2019.

15. Van Doorslaer E, Clarke P, Savage E, Hall J. Horizontal inequities in Australia's mixed public/private health care system. Health Policy. 2008:86(1):97-108.

16. Willis E, Parry Y. The Australian health care system. In: Willis E, Reynolds L, Keleher $\mathrm{H}$, editors. Understanding the Australian health care system. Chatswood: Elsevier; 2016. p. 232-77.

17. Cheng TC. Measuring the effects of reducing subsidies for private insurance on public expenditure for health care. J Health Econ. 2014:33:159-79.

18. Ellis RP, Savage E. Run for cover now or later? The impact of premiums, threats and deadlines on private health insurance in Australia. Int J Health Care Finance Econ. 2008;8(4):257-77. 
19. Tapay N, Colombo F. Private health insurance in OECD countries: the benefits and costs for individuals and health systems. Towards highperforming health systems: Policy Studies. 2004:265-319.

20. Department of Health. Australia's health system-an overview. Canberra: Department of Health; 2015. Available from: https://www.health.gov.au/ about-us/the-australian-health-system.

21. Duckett S, Willcox S. The Australian health care system: Oxford University press; 2015.

22. Australian Institute of Health and Welfare. Hospital resources 2016-17: Australian hospital statistics. Canberra: Australian Institute of Health and Welfare; 2018. Available from: https://www.aihw.gov.au/reports/hospitals/ ahs-2016-17-hospital-resources/data.

23. Australian Institute of Health and Welfare Private health insurance usein Australian hospitals, 2006-07 to 2015-16. Australian hospital statistics. Canberra: AlHW: Health Services Series no. 81. Cat. no. HSE 196. Australian Institute of Health and Welfare; 2017.

24. Van Gameren E. Health insurance and use of alternative medicine in Mexico. Health Policy. 2010;98(1):50-7.

25. Folland S, Goodman AC, Stano M. The economics of health and health care: Pearson prentice Hall upper Saddle River, NJ; 2007.

26. Department of Social Services. The Household, Income and Labour Dynamics in Australia (HILDA) Survey, GENERAL RELEASE 16 (Waves 1-16). ADA Dataverse, V4. 2017.

27. Butterworth P, Leach LS, Rodgers B, Broom DH, Olesen SC, Strazdins L. Psychosocial job adversity and health in Australia: analysis of data from the HILDA survey. Aust N Z J Public Health. 2011;35(6):564-71.

28. Summerfield M, Bevitt A, Freidin S, Hahn M, La N, Macalalad N, et al. HILDA user manual - Release 16'. Melbourne Institute of Applied Economic and Social Research, University of Melbourne. 2017. Available from: https:// melbourneinstitute.unimelb.edu.au/_data/assets/pdf_file/0006/2597865/ HILDA-User-Manual-Release-16.0_LATEST.pdf.

29. Wooden $M$, Watson $N$. The HILDA survey and its contribution to economic and social research (so far). Econ Rec. 2007;83(261):208-31.

30. Pagán JA, Puig A, Soldo BJ. Health insurance coverage and the use of preventive services by Mexican adults. Health Econ. 2007;16(12):1359-69.

31. Dismuke CE, Egede LE. Association of serious psychological distress with health services expenditures and utilization in a national sample of US adults. Gen Hosp Psychiatry. 2011:33(4):311-7.

32. Grossman M. On the concept of health capital and the demand for health J Polit Econ. 1972;80(2):223-55.

33. Monheit AC, Grafova IB, Kumar R. How does family health care use respond to economic shocks? Realized and anticipated effects. Rev Econ Household. 2018;18:307-34. https://doi.org/10.1007/s11150-018-9438-9.

34. Jeon B, Kwon S. Effect of private health insurance on health care utilization in a universal public insurance system: a case of South Korea. Health Policy. 2013;113(1-2):69-76.

35. Australian Bureau of Statistics. ASGC remoteness classification: purpose and use (Census Paper No. 03/01). Canberra: ACT: Commonwealth of Australia 2003; 2003. p. 2-20.

36. Booth-Kewley S, Vickers RR Jr. Associations between major domains of personality and health behavior. J Pers. 1994:62(3):281-98.

37. Jowett $M$, Contoyannis $P$, Vinh ND. The impact of public voluntary health insurance on private health expenditures in Vietnam. Soc Sci Med. 2003; 56(2):333-42.

38. Zhang L, Ding D, Neubeck L, Gallagher P, Paull G, Gao Y, et al. Mobile technology utilization among patients from diverse cultural and linguistic backgrounds attending cardiac rehabilitation in Australia: descriptive, CaseMatched Comparative Study. JMIR Cardio. 2018;2(1):e13.

39. Field A. Discovering statistics using IBM SPSS statistics. 5th ed. London: Sage; 2013

40. Wright DB, London K, Field AP. Using bootstrap estimation and the plug-in principle for clinical psychology data. J Exp Psychopathol. 2011;2(2):252-70 jep. 013611

41. Buchmueller T. Community rating, entry-age rating and adverse selection in private health insurance in Australia. The Geneva Papers on Risk and Insurance-Issues and Practice. 2008:33(4):588-609.

42. Ungar WJ, Ariely R. Health insurance, access to prescription medicines and health outcomes in children. Expert Rev Pharmacoecon Outcomes Res. 2005;5(2):215-25.

43. Cheng TC, Haisken-DeNew JP, Yong J. Cream skimming and hospital transfers in a mixed public-private system. Soc Sci Med. 2015;132:156-64.
44. Duckett SJ. Living in the parallel universe in Australia: public Medicare and private hospitals. Can Med Assoc J. 2005;173(7):745-7.

45. Lu M, Savage E. Do financial incentives for supplementary private health insurance reduce pressure on the public system? Evidence from Australia. iHEA 2007 6th world congress: explorations in health economics paper. Sydney: University of Technology; 2006.

46. Armstrong BK, Gillespie JA, Leeder SR, Rubin GL, Russell LM. Challenges in health and health care for Australia. Med J Aust. 2007;187(9):485.

\section{Publisher's Note}

Springer Nature remains neutral with regard to jurisdictional claims in published maps and institutional affiliations.
Ready to submit your research? Choose BMC and benefit from:

- fast, convenient online submission

- thorough peer review by experienced researchers in your field

- rapid publication on acceptance

- support for research data, including large and complex data types

- gold Open Access which fosters wider collaboration and increased citations

- maximum visibility for your research: over $100 \mathrm{M}$ website views per year

At $\mathrm{BMC}$, research is always in progress.

Learn more biomedcentral.com/submissions 